\title{
One-year follow-up of the effects of sildenafil on pulmonary arterial hypertension and veno-occlusive disease
}

A.C. Barreto, S.M. Franchi, C.R.P. Castro and A.A. Lopes
Departamento de Cardiologia Pediátrica e Cardiopatias Congênitas, Instituto do Coração, Faculdade de Medicina, Universidade de São Paulo, São Paulo, SP, Brasil

\section{Correspondence}

A.A. Lopes

Departamento de Cardiologia

Pediátrica e Cardiopatias Congênitas

InCor, FM, USP

Av. Dr. Eneas C. Aguiar, 44

05403-000 São Paulo, SP

Brasil

Fax: +55-11-3069-5347

E-mail: aablopes@usp.br

Publication supported by FAPESP.

.....................

Received March 10, 2004

Accepted October 1, 2004

\begin{abstract}
We hypothesized that chronic oral administration of the phosphodiesterase-5 inhibitor sildenafil could improve the exercise capacity and pulmonary hemodynamics in patients with pulmonary arterial hypertension (PAH) on the basis of previous short-term studies. We tested this hypothesis in 14 subjects with $\mathrm{PAH}$, including seven patients with the idiopathic form and seven patients with atrial septal defects, but no other congenital heart abnormalities. Patients were subjected to a 6min walk test and dyspnea was graded according to the Borg scale. Pulmonary flow and pressures were measured by Doppler echocardiography. Patients were given sildenafil, $75 \mathrm{mg}$ orally three times a day, and followed up for 1 year. Sildenafil therapy resulted in the following changes: increase in the 6-min walk distance from a median value of $387 \mathrm{~m}$ (range 0 to $484 \mathrm{~m}$ ) to $462 \mathrm{~m}$ (range 408 to $588 \mathrm{~m}$; P < 0.01), improvement of the Borg dyspnea score from 4.0 (median value) to 3.0 $(\mathrm{P}<0.01)$, and increased pulmonary flow (velocity-time integral) from a median value of 0.12 (range 0.08 to 0.25 ) to 0.23 (range 0.11 to $0.40 ; \mathrm{P}<0.01$ ) with no changes in pulmonary pressures. In one patient with pulmonary veno-occlusive disease diagnosed by a lung biopsy, sildenafil had a better effect on the pulmonary wedge pressure than inhaled nitric oxide (15 and $29 \mathrm{mmHg}$, respectively, acute test). He walked $112 \mathrm{~m}$ at baseline and $408 \mathrm{~m}$ at one year. One patient died at 11 months of treatment. No other relevant events occurred. Thus, chronic administration of sildenafil improves the physical capacity of $\mathrm{PAH}$ patients and may be beneficial in selected cases of veno-occlusive disease.
\end{abstract}

\section{Introduction}

Conventional vasodilator therapy for pulmonary arterial hypertension (PAH), which includes calcium channel blockers, has been shown to have an impact on survival (1),
Key words

- Sildenafil

- Pulmonary hypertension

- Pulmonary veno-occlusive disease

- Phosphodiesterase inhibitors although the responders represent a limited proportion of treated patients. From 1990 to 2000, sequential studies demonstrated the beneficial effects of continuous intravenous prostacyclin (epoprostenol) infusion on the physical capacity, hemodynamics and sur- 
vival of patients with PAH (2-7). Subsequently, since 2000, controlled clinical trials have demonstrated the efficacy of novel prostacyclin analogues developed for oral (8), subcutaneous (9) and inhaled (10) therapy. In addition, based on the important pathophysiological role of endothelin-1 in PAH $(11,12)$, the endothelin receptor antagonist bosentan has been tested successfully $(13,14)$.

In the last 2 to 3 years, additional new compounds have been tested and are in different phases of approval by regulatory agencies. These new therapeutic options include sildenafil, a specific phosphodiesterase-5 inhibitor which is expected to promote a sustained rise in cGMP levels within pulmonary vascular smooth muscle cells. This would enhance the vasodilator effects of endogenous nitric oxide and natriuretic peptides $(15,16)$. The rationale for using sildenafil as a pulmonary vasodilator is that the high concentration of phosphodiesterase-5 in lung tissue (17) would cause its effect to be more restricted to the pulmonary circulation.

Most of the accumulated knowledge on the use of sildenafil in pulmonary hypertension is based on case reports or observation of small patient groups (18-23). There are few studies involving more than 10 patients (24-26). In some of them, the acute effects of sildenafil on the pulmonary circulation were examined (27-29). In others, the drug was tested in specific clinical conditions such as lung fibrosis (30) and thromboembolic pulmonary hypertension (31). The objective of the present study was to investigate the longterm effects of oral sildenafil administration on the physical capacity of patients with $\mathrm{PAH}$. We also investigated whether improvement of exercise tolerance, if any, would be associated with changes in pulmonary hemodynamics estimated noninvasively. We included in the study patients with severe PAH who could not walk any distance at baseline, and one case of well-documented pulmonary veno-occlusive disease (PVOD).
After baseline evaluation, patients were followed up for at least 1 year.

\section{Patients and Methods}

\section{Patient group}

The study included patients with PAH who were admitted to the Heart Institute, São Paulo, Brazil, for diagnosis and treatment from March, 2002 to February, 2003. In order to make the patient population as homogeneous as possible, only patients with idiopathic PAH (sporadic or familial) or advanced pulmonary vasculopathy associated with an atrial septal defect were included. These patients entered the study consecutively. Patients with chronic airway obstruction, pulmonary thromboembolism, connective tissue disease, and schistosomiasis were excluded. In our patient population, there was no history of fenfluramine ingestion and no clinical or laboratory evidence of human immunodeficiency virus infection. A mean pulmonary artery pressure above $30 \mathrm{mmHg}$ at rest in the presence of normal pulmonary artery wedge pressure $(<15 \mathrm{mmHg})$, obtained during cardiac catheterization before the study, was considered necessary for patient inclusion. Patients with class II to IV symptoms (New York Heart Association) entered the study if they were stable and assisted on an outpatient basis. They were enrolled if they walked a maximum of $500 \mathrm{~m}$ during the 6-min walk test, although we did not establish any lower limit for inclusion. During the study, patients were kept on anticongestive therapy (cardiac glycosides and diuretics) if necessary, as well as warfarin. However, no vasodilators other than sildenafil were used prior to or during the study. In particular, prostacyclin analogues and bosentan were not administered to any patient. The protocol was approved by the Scientific Committee of the Heart Institute (SDC 2072/02/79) and the local ethics committee (CAPPesq 851/02) and patients gave written informed 
consent to participate in the study.

\section{Study protocol}

Having met the criteria for inclusion, patients were hospitalized for pre-treatment (baseline) evaluation and for the first $72 \mathrm{~h}$ of drug administration. Evaluation consisted of a 6-min walk test, classification of dyspnea at rest and at the end of the walk test according to the Borg criteria, and echocardiographic estimation of pulmonary pressures and flow. Systemic parameters were also recorded. Patients were given sildenafil 75 mg orally three times a day, and tests were repeated at $72 \mathrm{~h}$. Those who did not have any significant adverse events were kept on therapy. At 6 months, an attempt was made to reduce the sildenafil dose to $50 \mathrm{mg}$ three times a day. Subsequent evaluations were performed at 3 months, 6 months and 1 year. All patients were kept on sildenafil after the end of the study period. Follow-up information on patients who have been treated for 12 to 22 months is also provided.

\section{Outcome measures}

The 6-min walk test, which consists of determining the distance a patient could walk in $6 \mathrm{~min}$, was performed according to a standardized protocol (32). The perceived patient breathlessness at rest and at the end of the 6-min walk was graded according to the Borg dyspnea scale which consists of scores of 0 to 10 , with higher values indicating more severe discomfort (33). Rest and post-exercise peripheral oxygen saturation was measured by pulse oximetry. Doppler echocardiographic estimation of pulmonary hemodynamics was carried out as previously described (34). Briefly, pulmonary pressures were estimated using continuous-wave Doppler recording. The systolic pulmonary artery pressure, assumed to be equal to the systolic right ventricular pressure, was determined using the maximal tricuspid regur- gitation jet velocity. The mean and diastolic pulmonary artery pressures were obtained from the curve of pulmonary regurgitation. Pulmonary flow was estimated using pulsed Doppler recording, with the cursor positioned in the midpoint of the pulmonary annulus. The systolic flow velocity was recorded as a function of time. The area under the curve was calculated and reported as the velocitytime integral (VTI). Heart rate and mean systemic pressure were measured noninvasively. In one patient with documented PVOD, an acute vasodilator trial with sildenafil was performed with invasive assessment of cardiopulmonary hemodynamics (right heart catheterization).

\section{Safety procedures}

Laboratory tests including evaluation of hepatic and renal function as well as complete ophthalmologic examination were performed at baseline and every 3 months for all subjects receiving sildenafil. As an attempt to detect any adverse effects or changes in the clinical status, patients underwent medical evaluation every 2 weeks for 6 months and monthly thereafter.

\section{Statistical analysis}

The null hypothesis of the study was that there would be no differences between results obtained during sildenafil therapy and those obtained at baseline. The most important variables in the study, e.g., the 6-min walk distance, the Borg dyspnea score and pulmonary VTI and pressures could not be assumed to have normal (Gaussian) distribution. We therefore decided to express all the results as median and range. Results obtained at 72 h, 3 months, 6 months, and 1 year of treatment were compared with baseline values as repeated measures in the same subject. For this purpose, Friedman's test (so-called Friedman's ANOVA) was used first. If differences were detected, the New- 
man-Keuls multiple comparison test was applied in an attempt to determine which specific values were significantly different from baseline. All tests were two-sided. The null hypothesis was rejected in the presence of $\mathrm{P}$ values $<0.05$.

\section{Results}

\section{General patient data}

Individual patient data at baseline are listed in Table 1. Fourteen patients (11 females) aged $33 \pm 12$ years (median 31 , range 15 to 53 years) were enrolled. Except for 2 patients, the time of symptoms prior to the study ranged from 2 months to 3 years (median 1 year) in the idiopathic PAH group and 1 to 3 years (median 1 year) in the atrial septal defect group. Two patients, one in each group, had a more insidious disease, with a duration of 10 and 14 years, respectively. The mean pulmonary arterial pressure was $50 \pm 11 \mathrm{mmHg}$. Two patients (cases No. 8 and 9, brother and sister) had familial
PAH. In one patient (case No. 12), a preliminary diagnosis of familial PAH was established, but he was further confirmed to have PVOD by hemodynamic evaluation and a lung biopsy. The 6-min walk distance at baseline was shorter than $150 \mathrm{~m}$ for 4 patients. Two of them could not walk at all.

\section{Sildenafil therapy}

The effects of sildenafil on the parameters analyzed in the study are shown in Tables 2, 3 and 4 and Figures 1 and 2. Patient No. 14 presented moderate to severe headaches and abdominal as well as leg pain. Sildenafil was discontinued on the second day. Patient No. 6 was lost to follow-up after the 3-month evaluation, since she moved to another state in Brazil. We were informed that she is under medical care and stable. Patient No. 4 died after 11 months of treatment (see follow-up data). Thus, the effects of treatment were computed at 3 months, 6 months, and 1 year in 13,12 and 11 patients, respectively.

\begin{tabular}{|c|c|c|c|c|c|c|c|c|}
\hline $\begin{array}{l}\text { Patient } \\
\text { No. }\end{array}$ & Gender & $\begin{array}{c}\text { Age } \\
\text { (years) }\end{array}$ & Diagnosis & $\begin{array}{l}\text { Mean pulmonary } \\
\text { arterial pressure } \\
(\mathrm{mmHg})\end{array}$ & $\begin{array}{c}\mathrm{SpO}_{2} \\
(\%)\end{array}$ & NYHA & $\begin{array}{l}6^{\prime} W D \\
(\mathrm{~m})\end{array}$ & $\begin{array}{c}\text { Borg dyspnea } \\
\text { score }\end{array}$ \\
\hline 1 & $\mathrm{~F}$ & 42 & ASD & 47 & 74 & III & 409 & 5 \\
\hline 2 & $\mathrm{~F}$ & 53 & Idiopathic PAH & 56 & 96 & IV & 175 & 5 \\
\hline 3 & $\mathrm{~F}$ & 36 & ASD & 54 & 96 & $\|$ & 484 & 4 \\
\hline 4 & $\mathrm{~F}$ & 24 & Idiopathic PAH & 60 & 97 & IV & 0 & $5^{*}$ \\
\hline 5 & $\mathrm{~F}$ & 37 & Idiopathic PAH & 34 & 94 & III & 387 & 5 \\
\hline 6 & $\mathrm{~F}$ & 23 & ASD & 42 & 96 & $\|$ & 392 & 4 \\
\hline 7 & $M$ & 46 & Idiopathic PAH & 33 & 96 & $\|$ & 379 & 4 \\
\hline 8 & M & 15 & Familial PAH & 62 & 99 & IV & 0 & $4^{*}$ \\
\hline 9 & $\mathrm{~F}$ & 18 & Familial PAH & 50 & 98 & $\|$ & 406 & 3 \\
\hline 10 & $\mathrm{~F}$ & 29 & ASD & 63 & 97 & $\|$ & 439 & 4 \\
\hline 11 & $\mathrm{~F}$ & 53 & ASD & 42 & 96 & III & 363 & 5 \\
\hline 12 & M & 33 & Familial $\mathrm{PAH}^{+}$ & 62 & 92 & IV & 112 & 6 \\
\hline 13 & $\mathrm{~F}$ & 25 & ASD & 61 & 94 & III & 413 & 4 \\
\hline 14 & $\mathrm{~F}$ & 25 & ASD & 38 & 97 & III & 96 & 4 \\
\hline
\end{tabular}

ASD = atrial septal defect; NYHA = New York Heart Association Classification; $\mathrm{PAH}=$ pulmonary arterial hypertension; $\mathrm{SpO}_{2}$ = peripheral oxygen saturation; 6' WD =6-min walk distance. ${ }^{*}$ The score corresponds to the magnitude of breathlessness at rest for the 2 patients who could not walk at baseline. The Borg dyspnea score is described in Ref. 33. +Familial pulmonary arterial hypertension presenting as pulmonary veno-occlusive disease. 
In the patient group as a whole, sildenafil did not provoke significant changes in pulmonary pressures measured noninvasively. However, there was a significant increase in pulmonary VTI at $72 \mathrm{~h}(\mathrm{P}<0.05), 3$ months $(\mathrm{P}<0.05), 6$ months $(\mathrm{P}<0.01)$, and 1 year $(\mathrm{P}$ $<0.01$ ) relative to baseline (Figure 1A). This was associated with a significant increase in the median value of the walk distance at 3 months, 6 months and 1 year relative to the basal condition $(\mathrm{P}<0.01$; Figure $1 \mathrm{~B})$. Individual changes in the 6-min walk distance are shown in Figure 2. All patients who completed a one-year follow-up on sildenafil walked more than $380 \mathrm{~m}$ at that time. Patients with idiopathic PAH walked a shorter distance at baseline in comparison with those with atrial septal defects (277 and $413 \mathrm{~m}$, respectively, median values), but the distance walked at 1 year was very similar (466 and $462 \mathrm{~m}$, respectively). The increase was significant in both groups $(\mathrm{P}=0.028$ and $\mathrm{P}=$ 0.043 , respectively). The increase in walk distance was associated with improvement in the Borg dyspnea score at 3 months $(\mathrm{P}<$ 0.05), 6 months $(\mathrm{P}<0.05)$ and 1 year $(\mathrm{P}<$ 0.01 ) versus baseline (Figure 1C). As shown in Table 2, no significant changes were detected in systemic parameters during sildenafil therapy.

\section{Sildenafil treatment for pulmonary veno-occlusive disease}

One patient (case No. 12) had an initial diagnosis of familial PAH based on clinical presentation and relevant familial events. Two sisters of his died of pulmonary hypertension at 11 and 14 years of age. Subsequently, this patient was shown to have PVOD based on a lung biopsy (data not shown) and hemodynamic behavior during an acute vasodilator trial (Table 3 ). In this patient, no abnormalities of the left heart were detected during echocardiographic examination. In particular, pulmonary venous drainage, left atrium, mitral valve, and left ventricle were normal. The left ventricular ejection fraction was $75 \%$. After a single oral dose of $75 \mathrm{mg}$ sildenafil, there was a marked decrease in pulmonary vascular resistance, similar to the effect obtained with $10 \mathrm{ppm}$ inhaled nitric oxide. In contrast to nitric oxide, however, the rise in pulmonary artery wedge pressure was only mild and well tolerated. Based on these results, the
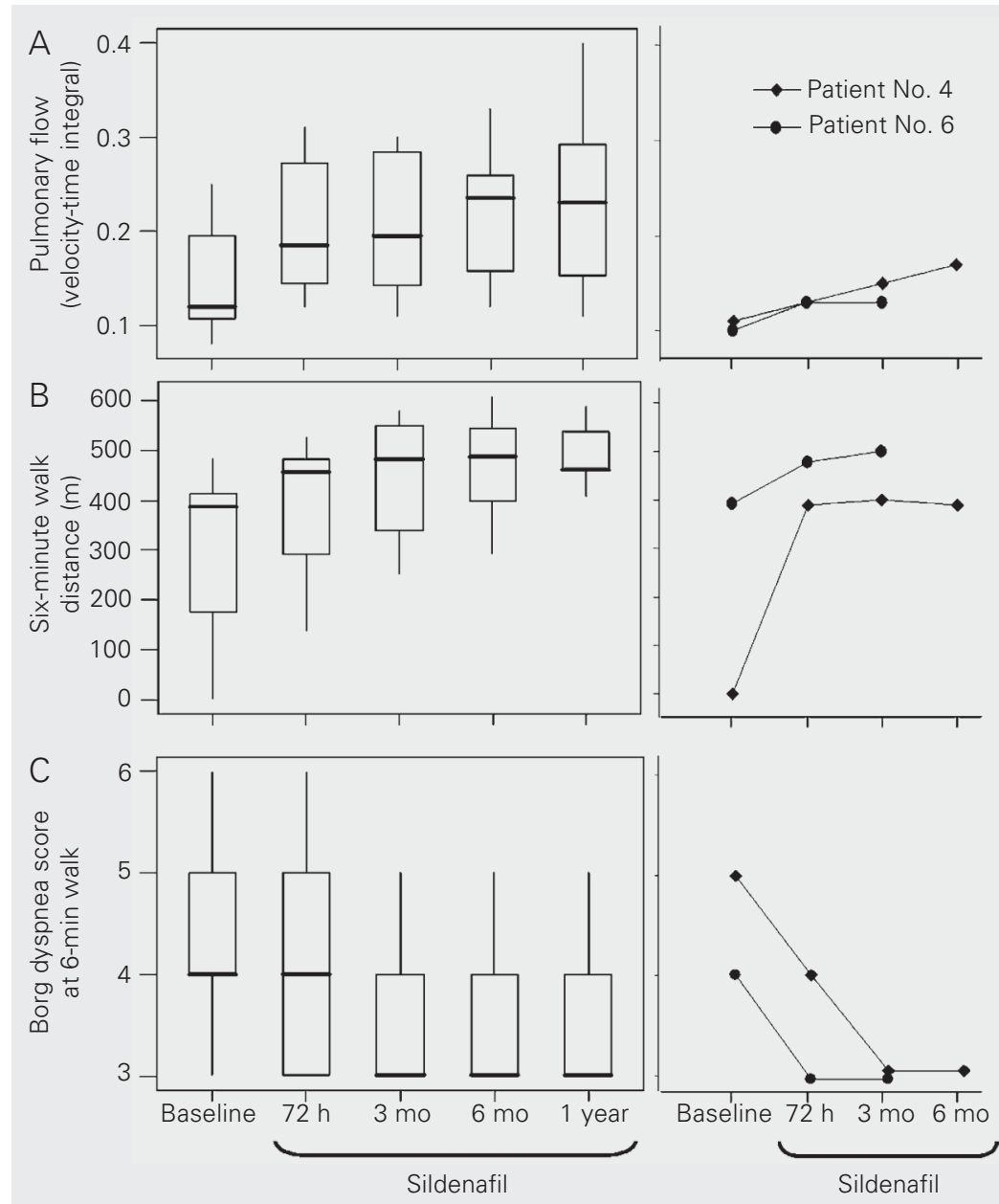

Figure 1. Box-plot representation of the effect of sildenafil on pulmonary hypertensive patients who were followed for one year. The dose was $75 \mathrm{mg}$ three times a day for six months and was reduced afterwards to $50 \mathrm{mg}$ three times a day in all but five patients. Shown on the right are the individual data for two patients who did not complete follow-up (see text). A, Effect of sildenafil on pulmonary flow (velocity-time integral; $\mathrm{P}=0.0007$, Friedman's ANOVA). The multiple comparison test showed significant differences at $72 \mathrm{~h}$ $(P<0.05), 3$ months $(P<0.05), 6$ months $(P<0.01)$, and 1 year $(P<0.01)$ relative to baseline. $B$, Effect of sildenafil on the 6 -min walk distance $(P<0.0001)$. The increase was significant at 3 months, 6 months and 1 year $(P<0.01)$. $C$, Effect of sildenafil on Borg dyspnea score at the end of the 6 -min walk $(P=0.0033)$. The decrease was significant at 3 months $(P<0.05), 6$ months $(P<0.05)$ and 1 year $(P<0.01) .3$ and 6 mo $=3$ and 6 months. 
Figure 2. Changes in the 6-min walk distance of $11 \mathrm{PAH}$ patients on sildenafil therapy for 1 year in comparison with pretreatment (baseline) condition. Sildenafil dose was the same as indicated in Figure 1. The patient number given in the inset is the same as in Table 1. The horizontal line corresponds to $380 \mathrm{~m} .3$ and $6 \mathrm{mo}=3$ and 6 months. patient was enrolled in the sildenafil study group and was stable at 1 year on treatment, with the pulmonary and systemic parameters indicated in Table 4. This patient was excluded from the lung transplantation waiting list after 6 months of sildenafil therapy.

\section{Adverse effects and relevant follow-up events}

Data analysis was carried out when the last patient completed 1 year of follow-up (February 2004). The first patient who en-

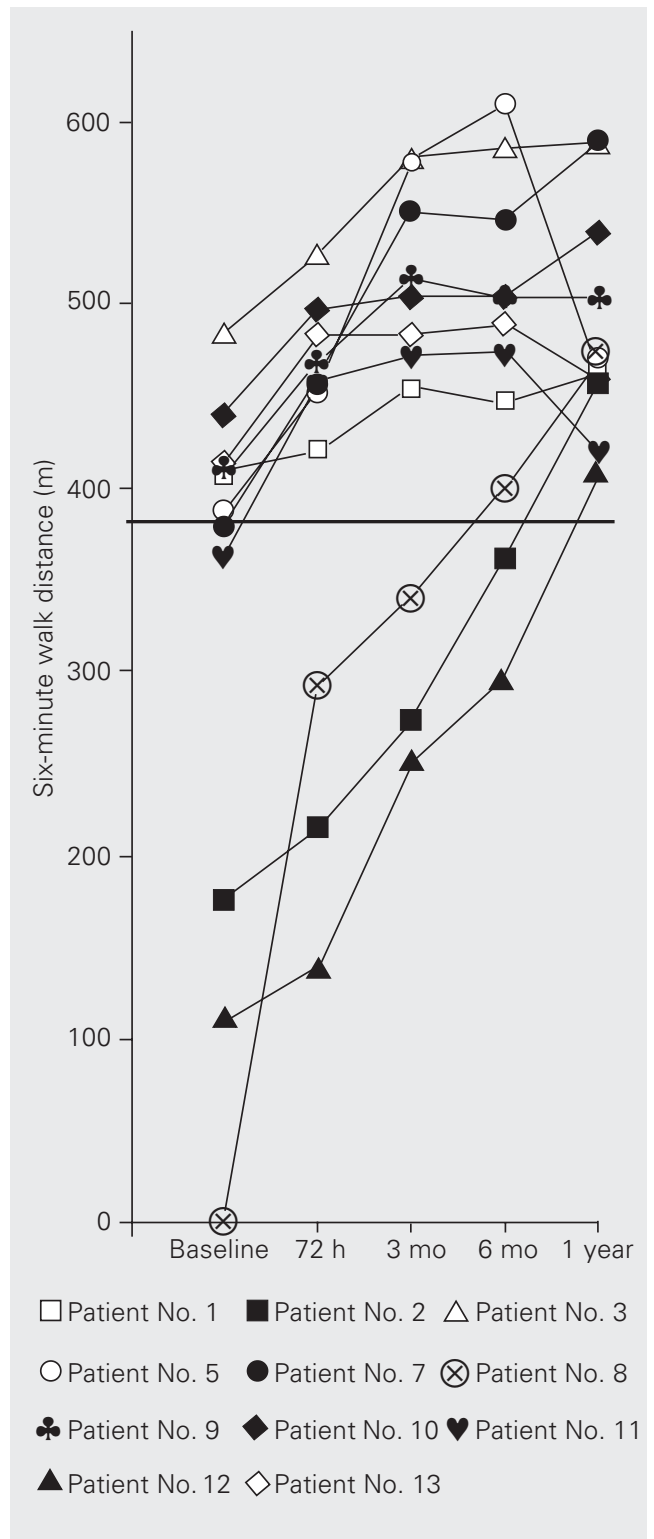

tered the study has now been treated for 22 months (patient No. 1; Table 1). Thus, the duration of follow-up in the present study group ranged from 12 to 22 months. Eleven of 14 patients who entered the study are currently on chronic use of sildenafil as the single vasodilator therapy.

The following events were observed during the first few days of treatment: headache $(\mathrm{N}=5)$, abdominal pain $(\mathrm{N}=2)$, leg pain $(\mathrm{N}$ $=1)$, nausea $(\mathrm{N}=2)$, diarrhea $(\mathrm{N}=1)$, and a color tinge to vision $(\mathrm{N}=1)$. Except for one patient with moderate to severe abdominal and leg pain whose treatment was discontinued (case No. 14), symptoms were mild, self-limited and did not require any specific treatment or changes in sildenafil schedule. No changes were detected in hepatic or renal function and no ophthalmologic abnormalities were observed during follow-up. Increased skin pigmentation in the face associated with sun exposure was observed in 3 patients (cases No. 1, 3 and 5). After 6 months of treatment, an attempt was made to reduce the sildenafil dose to $50 \mathrm{mg}$ three times a day. Five patients did not tolerate dose reduction (cases No. 4, 5, 8, 11, and 12) but improved after returning to the initial dose. At 11 months of treatment, patient No. 4 appeared at the emergency unit with syncope and circulatory collapse. In spite of intensive care, she died 4 days after admission. Permission for autopsy examination was not obtained.

\section{Discussion}

In this study of chronic sildenafil administration in $\mathrm{PAH}$, all patients improved in their physical capacity compared with baseline. This was associated with an increase in estimated pulmonary flow in all patients and improvement in Borg dyspnea score in all but 2 patients. The drug appeared to be effective in patients with class IV symptoms, in particular 2 subjects who could not walk before treatment. All patients who walked 
Table 2. Effect of sildenafil on pulmonary, systemic and exercise parameters.

\begin{tabular}{|c|c|c|c|c|c|}
\hline & \multirow[t]{2}{*}{ Baseline } & \multicolumn{4}{|c|}{ Sildenafil } \\
\hline & & $72 \mathrm{~h}$ & 3 months & 6 months & 1 year \\
\hline 6-min walk distance (m) & $387(0-484)$ & $457(138-527)$ & $483(252-579) * *$ & $489(294-609)^{* *}$ & $462(408-588)^{* *}$ \\
\hline \multicolumn{6}{|l|}{ Borg dyspnea score } \\
\hline Rest & $2.0(0-5.0)$ & $2.0(0-5.0)$ & $1.0(0-3.0)$ & $1.0(0-3.0)$ & $1.0(0-2.0)^{*}$ \\
\hline 6-min walk & $4.0(3.0-6.0)$ & $4.0(3.0-6.0)$ & $3.0(3.0-5.0)^{*}$ & $3.0(3.0-5.0)^{*}$ & $3.0(3.0-5.0)^{* *}$ \\
\hline \multicolumn{6}{|l|}{$\begin{array}{l}\text { Pulmonary artery } \\
\text { pressure }(\mathrm{mmHg})\end{array}$} \\
\hline Systolic & $107(68-150)$ & $98(66-152)$ & $118(80-150)$ & $110(60-145)$ & $106(77-167)$ \\
\hline Diastolic & $37(13-42)$ & $31(16-37)$ & $31(24-44)$ & $29(21-47)$ & $26(23-44)$ \\
\hline Mean & $54(33-63)$ & $43(28-60)$ & $46(35-63)$ & $50(30-72)$ & $45(33-74)$ \\
\hline Pulmonary flow (VTI) & $0.12(0.08-0.25)$ & $0.19(0.12-0.31)^{*}$ & $0.19(0.11-0.30)^{*}$ & $0.24(0.12-0.33)^{* *}$ & $0.23(0.11-0.40)^{* *}$ \\
\hline $\begin{array}{l}\text { Mean systemic } \\
\text { pressure }(\mathrm{mmHg})\end{array}$ & 76 (69-93) & 77 (70-93) & $80(70-93)$ & $79(69-92)$ & $83(73-93)$ \\
\hline Heart rate (bpm) & $76(55-100)$ & $76(68-85)$ & $75(66-90)$ & $84(60-87)$ & $75(58-92)$ \\
\hline \multicolumn{6}{|l|}{$\mathrm{SpO}_{2}(\%)$} \\
\hline Rest & 96 (74-99) & 96 (87-98) & 97 (86-98) & $96(80-97)$ & $96(77-98)$ \\
\hline 6-min walk & 90 (46-99) & $91(69-98)$ & $92(65-98)$ & 93 (59-98) & $90(56-97)$ \\
\hline
\end{tabular}

Data are reported as median and range. $\mathrm{SpO}_{2}=$ peripheral oxygen saturation; $\mathrm{VTI}=$ velocity-time integral.

${ }^{*} P<0.05$ and ${ }^{*} P<0.01$ versus baseline (Newman-Keuls multicomparison test after Friedman's ANOVA).

Table 3. Acute vasodilator trial in a patient with pulmonary veno-occlusive disease.

\begin{tabular}{lccc}
\hline & Baseline & Nitric oxide (10 ppm) & Sildenafil $^{*}$ \\
\hline Mean systemic pressure $(\mathrm{mmHg})$ & 78 & 78 & 76 \\
Mean pulmonary artery pressure $(\mathrm{mmHg})$ & 61 & 48 & 44 \\
Pulmonary artery wedge pressure $(\mathrm{mmHg})$ & 8 & 29 & 15 \\
Cardiac index (I min $\left.{ }^{-1} \mathrm{~m}^{-2}\right)$ & 1.9 & 2.3 & 2.6 \\
Pulmonary vascular resistance index $\left(\mathrm{U} / \mathrm{m}^{2}\right)$ & 27.9 & 8.3 & 11.1 \\
Systemic vascular resistance index $\left(\mathrm{U} / \mathrm{m}^{2}\right)$ & 39.4 & 34.3 & 31.5 \\
\hline
\end{tabular}

*Measurements performed on patient No. 12, $2 \mathrm{~h}$ after a single oral dose of $75 \mathrm{mg}$.

Table 4. Chronic effect of sildenafil on pulmonary veno-occlusive disease (patient No. 12).

\begin{tabular}{lcccc}
\hline & Baseline & 3 months & 6 months & 1 year \\
\hline Six-minute walk distance $(\mathrm{m})$ & 112 & 252 & 294 & 408 \\
Borg dyspnea score & 6 & 5 & 5 & 4 \\
Mean pulmonary artery pressure $(\mathrm{mmHg})$ & 62 & 35 & 54 & 48 \\
Pulmonary flow (VTI) & 0.10 & 0.15 & 0.15 & 0.22 \\
Mean systemic pressure $(\mathrm{mmHg})$ & 76 & 80 & 73 & 83 \\
\hline
\end{tabular}

Sildenafil was administered orally, $75 \mathrm{mg}$ three times a day. VTI = velocity-time integral. 
less than $380 \mathrm{~m}$ at baseline were above this limit at the end of the study period. Ability to walk more than $380 \mathrm{~m}$ during vasodilator therapy has been shown to be associated with a better prognosis in pulmonary hypertension (35). Finally, in one patient with a confirmed diagnosis of PVOD, chronic administration of sildenafil was effective and safe. Thus, the major contribution of the present study to the literature of sildenafil in PAH may be summarized as follows. The drug seems to be effective on a long-term basis, even in patients with severily disabling disease (idiopathic PAH and atrialseptal defect-associated PAH). Also, sildenafil seems to be useful in selected cases of veno-occlusive disease.

Although there are similarities in the pathological features of pulmonary hypertension of varying etiologies, abnormalities at the cellular and molecular levels may be different. Thus, inflammatory mechanisms are present in idiopathic PAH but there is no available information on the role played by inflammation in PAH associated with atrial septal defects. In spite of these potential differences, we observed a beneficial effect of sildenafil on the physical capacity of patients with both etiologies.

Side effects that may occur over time in individual patients using sildenafil are difficult to predict at present. In a recent series (24), no major adverse effects were reported with doses up to $300 \mathrm{mg} /$ day. A significant decrease in systemic pressure requiring drug discontinuation has been reported with a daily dose of $150 \mathrm{mg}$ (25). In our study, a daily dose of $225 \mathrm{mg}$ sildenafil was well tolerated by all but one patient who presented moderate to severe headaches associated with abdominal and leg pain. A fatal outcome has been reported in patients on long-term sildenafil therapy. In a recent study (25), 2 of 14 patients died after 6 and 7 months of treatment. In one of them, the fatal outcome was associated with the onset of atrial fibrillation. One of our patients died after 11 months of treatment. Although we cannot definitely exclude the possibility of a serious adverse effect of the drug, this patient had an excellent initial response to treatment, with an increase in walk distance from $0 \mathrm{~m}$ at baseline to 399 and $389 \mathrm{~m}$, respectively, at 3 and 6 months on sildenafil. Since permission for autopsy examination was not given, we can only speculate about pulmonary embolism as a possible cause of the fatal outcome.

The optimal daily dose of sildenafil in terms of efficacy and safety has not been established. Favorable effects have been reported with doses ranging from $25 \mathrm{mg}$ twice to $100 \mathrm{mg}$ three times a day (22-25). There seem to be patients who do not tolerate doses higher than $75 \mathrm{mg} /$ day (36). In our series, the dose of $75 \mathrm{mg}$ three times a day was well tolerated by all but one patient. Data for a large number of treated patients are needed to establish the ideal daily dose of sildenafil for long-term administration. The dose to be used in the individual patient will depend on additional factors such as decision to use sildenafil as a single or combined vasodilator therapy $(36,37)$.

The magnitude of changes in pulmonary pressures following sildenafil administration is still a matter of debate. Favorable effects have been reported in patients with PAH (23) and in subjects with chronic pulmonary thromboembolism (31). Also, improvement of pulmonary hemodynamics has been demonstrated with sildenafil as a long-term adjunct therapy (26). We observed a significant rise in pulmonary flow after chronic sildenafil administration, not associated with significant changes in pulmonary pressures. Similar results have been reported by Sastry and colleagues (24). These discrepancies may be in part methodological. In our patients and those of Sastry and co-workers (24), pulmonary pressures were assessed noninvasively by Doppler echocardiography. This is in contrast to the direct (invasive) measurements performed in the former studies 
$(23,26,31)$. Echocardiographic estimation of pulmonary pressures may not be sufficiently sensitive to detect mild changes in pulmonary artery pressures. However, the increase in pulmonary flow in our patients, in agreement with previous studies, suggests a beneficial effect of sildenafil on pulmonary hemodynamics.

PVOD may occur as sporadic or familial cases and has pathogenetic connections with the so-called primary pulmonary hypertension. This was suggested by a recent observation in a patient with documented PVOD of a mutation in the bone morphogen protein receptor II gene with transmission among family members (38). There has been a lot of controversy about the use of vasodilators in PVOD. In some case reports on prostacyclin therapy, results ranged from success (39) to fatal outcome due to pulmonary edema (40). In the present study, a patient with typical histopathological features of PVOD and a family history of pulmonary hypertension had an important reduction in pulmonary vascular resistance after a single oral dose of $75 \mathrm{mg}$ sildenafil. In contrast to inhaled nitric oxide, the increase in pulmonary wedge pressure was only mild. This superior effect of sildenafil on the "wedge pressure" compared with inhaled nitric oxide has been demonstrated in PAH (28) but, to our knowledge, has never been reported in veno-occlusive disease. Based on our findings, we would like to suggest that sildenafil may be beneficial for selected patients with PVOD after an appropriate acute test.

The present study has obvious limitations. The small number of treated patients and the unavailability of a placebo group are the most important ones. However, the placebo effect is unlikely to explain the improvement of exercise capacity in some patients, in particular those with severe physical limitation at baseline.

In conclusion, the phosphodiesterase-5 inhibitor sildenafil appears to be effective in increasing the exercise capacity of patients with PAH. Furthermore, the drug seems to be relatively safe for chronic use. We observed no major adverse effects that could be directly associated with sildenafil therapy. Selectivity of action on the pulmonary circulation was suggested by the absence of any relevant effects on the systemic circulation. The differential effect of sildenafil on the pulmonary wedge pressure as compared with inhaled nitric oxide indicates its potential usefulness in selected cases of PVOD. Controlled studies involving patients followed up for longer periods of time are necessary to establish the impact of the drug on long-term outcome and survival.

\section{Acknowledgments}

We would like to acknowledge Pfizer Laboratórios do Brasil for kindly providing us with sildenafil. We also thank Mrs. Roseli Polo for technical assistance with the preparation of this manuscript.

\section{References}

1. Rich S, Kaufmann E \& Levy PS (1992). The effect of high doses of calcium-channel blockers on survival in primary pulmonary hypertension. New England Journal of Medicine, 327: 76-81.

2. Rubin LJ, Mendoza J, Hood M, McGoon M, Barst R, Williams WB, Diehl JH, Crow J \& Long W (1990). Treatment of primary pulmonary hypertension with continuous intravenous prostacyclin (epoprostenol). Results of a randomized trial. Annals of Internal Medicine, 112: 485-491.

3. Barst RJ, Rubin LJ, McGoon MD, Caldwell EJ, Long WA \& Levy PS (1994). Survival in primary pulmonary hypertension with long-term continuous intravenous prostacyclin. Annals of Internal Medicine, 121: 409-415

4. Barst RJ, Rubin LJ, Long WA et al. (1996). A comparison of continuous intravenous epoprostenol (prostacyclin) with conventional therapy for primary pulmonary hypertension. New England Journal of Medicine, 334: 296-301.

5. Rosenzweig EB, Kerstein D \& Barst RJ (1999). Long-term prostacyclin for pulmonary hypertension with associated congenital heart defects. Circulation, 99: 1858-1865.

6. Sanchez O, Humbert M, Sitbon O \& Simonneau G (1999). Treat- 
ment of pulmonary hypertension secondary to connective tissue diseases. Thorax, 54: 273-277.

7. Badesch DB, Tapson VF, McGoon MD et al. (2000). Continuous intravenous epoprostenol for pulmonary hypertension due to the scleroderma spectrum of disease. A randomized, controlled trial. Annals of Internal Medicine, 132: 425-434.

8. Galiè N, Humbert M, Vachiéry J-L et al. (2002). Effects of beraprost sodium, an oral prostacyclin analogue, in patients with pulmonary arterial hypertension: a randomized, double-blind, placebo-controlled trial. Journal of the American College of Cardiology, 39: 1496-1502.

9. Simonneau G, Barst RL, Galiè N et al. (2002). Continuous subcutaneous infusion of treprostinil, a prostacyclin analogue, in patients with pulmonary arterial hypertension. A double-blind, randomized, placebo-controlled trial. American Journal of Respiratory and Critical Care Medicine, 165: 800-804.

10. Olschewski H, Simonneau G, Galiè N et al. (2002). Inhaled iloprost for severe pulmonary hypertension. New England Journal of Medicine, 347: 322-329.

11. Giaid A, Yanagisawa M, Langleben D, Michel RP, Levy R, Shennib H, Kimura S, Masaki T, Duguid WP \& Stewart DJ (1993). Expression of endothelin-1 in the lungs of patients with pulmonary hypertension. New England Journal of Medicine, 328: 1732-1739.

12. Galiè N, Grigioni F, Bacchi-Reggiani L, Ussia GP, Parlangeli R, Catanzariti P, Boschi S, Brauzi A \& Magnani B (1996). Relation of endothelin-1 to survival in patients with primary pulmonary hypertension: 273. European Journal of Clinical Investigation, 26 (Suppl 1): 48 (Abstract).

13. Rubin LJ, Badesch DB, Barst RJ et al. (2002). Bosentan therapy for pulmonary arterial hypertension. New England Journal of Medicine, 346: 896-903.

14. Sitbon O, Badesh DB, Channick RN, Frost A, Robbins IM, Simonneau G, Tapson VF \& Rubin LJ (2003). Effects of the dual endothelin receptor antagonist Bosentan in patients with pulmonary arterial hypertension. A 1-year follow-up study. Chest, 124: 247-254.

15. Archer SL, Huang JM, Hampl V, Nelson DP, Shultz PJ \& Weir EK (1994). Nitric oxide and cGMP cause vasorelaxation by activation of a charybdotoxin-sensitive $\mathrm{K}$ channel by cGMP-dependent protein kinase. Proceedings of the National Academy of Sciences, USA, 91: 7583-7587.

16. Muramatsu M, Tyler RC, Gutkowska J, Klinger JR, Hill NS, Rodman DM \& McMurtry IF (1997). Atrial natriuretic peptide accounts for increased cGMP in hypoxia-induced hypertensive rat lungs. American Journal of Physiology, 272: L1126-L1132.

17. Corbin JD \& Francis SH (1999). Cyclic GMP phosphodiesterase-5: target of sildenafil. Journal of Biological Chemistry, 274: 1372913732.

18. Laupland KB, Helmersen D, Zygun DA \& Viner SM (2003). Sildenafil treatment of primary pulmonary hypertension. Canadian Respiratory Journal, 10: 48-50.

19. Singh B, Gupta R, Punj V, Ghose T, Sapra R, Grover DN \& Kaul U (2002). Sildenafil in the management of primary pulmonary hypertension. Indian Heart Journal, 54: 297-300.

20. Jackson G \& Chambers $J$ (2002). Sildenafil for primary pulmonary hypertension: short and long-term symptomatic benefit. International Journal of Clinical Practice, 56: 397-398.

21. Sayin T \& Zenci M (2002). Sildenafil in primary pulmonary hypertension - is there a subset of patients who respond favourably? Canadian Journal of Cardiology, 18: 676-678.

22. Watanabe H, Ohashi K, Takeuchi K, Yamashita K, Yokoyama T, Tran QK, Satoh H, Terada H, Ohashi H \& Hayashi H (2002). Sildenafil for primary and secondary pulmonary hypertension. Clinical Pharmacology and Therapeutics, 71: 398-402.

23. Michelakis ED, Tymchak W, Noga M, Webster L, Wu X-C, Lien D, Wang S-H, Modry D \& Archer SL (2003). Long-term treatment with oral sildenafil is safe and improves functional capacity and hemodynamics in patients with pulmonary arterial hypertension. Circulation, 108: 2066-2069.

24. Sastry BKS, Narasimhan C, Reddy NK \& Raju BS (2004). Clinical efficacy of sildenafil in primary pulmonary hypertension. A randomized, placebo-controlled, double-blind, crossover study. Journal of the American College of Cardiology, 43: 1149-1153.

25. Kothari SS \& Duggal B (2002). Chronic oral sildenafil therapy in severe pulmonary artery hypertension. Indian Heart Journal, 54: 404-409.

26. Ghofrani HA, Rose F, Schermuly RT et al. (2003). Oral sildenafil as a long-term adjunct therapy to inhaled iloprost in severe pulmonary arterial hypertension. Journal of the American College of Cardiology, 42: 158-164

27. Ghofrani HA, Wiedemann R, Rose F, Olschewski H, Schermuly RT, Weissmann N, Seeger W \& Grimminger F (2002). Combination therapy with oral sildenafil and inhaled iloprost for severe pulmonary hypertension. Annals of Internal Medicine, 136: 515-522.

28. Michelakis E, Tymchak W, Lien D, Webster L, Hashimoto K \& Archer S (2002). Oral sildenafil is an effective and specific pulmonary vasodilator in patients with pulmonary arterial hypertension. Comparison with inhaled nitric oxide. Circulation, 105: 2398-2403.

29. Leuchte HH, Schwaiblmair M, Baumgartner RA, Neurohr CF, Kolbe T \& Behr J (2004). Hemodynamic response to sildenafil, nitric oxide, and iloprost in primary pulmonary hypertension. Chest, 125: 580586.

30. Ghofrani HA, Wiedemann R, Rose F, Schermuly RT, Olschewski H, Weissmann N, Gunther A, Walmrath D, Seeger W \& Grimminger F (2002). Sildenafil for treatment of lung fibrosis and pulmonary hypertension: a randomized controlled trial. Lancet, 360: 895-900.

31. Ghofrani HA, Schermuly RT, Rose F et al. (2003). Sildenafil for longterm treatment of nonoperable chronic thromboembolic pulmonary hypertension. American Journal of Respiratory and Critical Care Medicine, 167: 1139-1141.

32. ATS Committee on Proficiency Standards for Clinical Pulmonary Function Laboratories (2002). ATS statement: guidelines for the sixminute walk test. American Journal of Respiratory and Critical Care Medicine, 166: 111-117

33. Borg GA (1982). Psychophysical bases of perceived exertion. Medicine and Science in Sports and Exercise, 14: 377-381.

34. Eysmann SB, Palevsky HI, Reichek N, Hackney K \& Douglas PS (1989). Two-dimensional and Doppler echocardiographic and cardiac catheterization correlates of survival in primary pulmonary hypertension. Circulation, 80: 353-360

35. Sitbon O, Humbert M, Nunes H, Parent F, Garcia G, Herve P, Rainisio M \& Simonneau G (2002). Long-term intravenous epoprostenol infusion in primary pulmonary hypertension. Prognostic factors and survival. Journal of the American College of Cardiology, 40: 780-788.

36. Stiebellehner L, Petkov V, Vonbank K, Funk G, Schenk P, Ziesche R \& Block LH (2003). Long-term treatment with oral sildenafil in addition to continuous IV epoprostenol in patients with pulmonary arterial hypertension. Chest, 123: 1293-1295.

37. Wilkens H, Guth A, König J, Forestier N, Cremers B, Hennen B, Bohm M \& Sybrecht GW (2001). Effect of inhaled iloprost plus oral sildenafil in patients with primary pulmonary hypertension. Circulation, 104: 1218-1222. 
38. Runo JR, Vnencak-Jones CL, Prince M et al. (2003). Pulmonary veno-occlusive disease caused by an inherited mutation in bone morphogenetic protein receptor II. American Journal of Respiratory and Critical Care Medicine, 167: 889-894.

39. Okumura O, Nagaya N, Kyotani S, Sakamaki F, Nakanishi N, Fukuhara S \& Yutani C (2002). Effects of continuous IV prostacyclin in a patient with pulmonary veno-occlusive disease. Chest, 122: 1096-1098.

40. Palmer S, Robinson LJ, Wang A, Gossage JR, Bashore T \& Tapson VF (1998). Massive pulmonary edema and death after prostacyclin infusion in a patient with pulmonary veno-occlusive disease. Chest, 113: $237-240$. 